\title{
Expression of delta-like ligand 4 (DII4) and markers of hypoxia in colon cancer
}

\author{
AM Jubb ${ }^{1,6}$, H Turley ${ }^{1,6}$, HC Moeller', G Steers', C Han ${ }^{2}$, J-L Li², R Leek', EY Tan', B Singh ${ }^{3}$, NJ Mortensen ${ }^{3}$, \\ I Noguera-Troise ${ }^{4}$, F Pezzella', KC Gatter', G Thurston ${ }^{4}$, SB Fox ${ }^{5,6}$ and AL Harris ${ }^{*, 1,6}$ \\ 'Nuffield Department of Clinical Laboratory Sciences, University of Oxford, John Raddliffe Hospital, Headington, Oxford OX3 9DS, UK; ${ }^{2}$ Weatherall \\ Institute of Molecular Medicine, University of Oxford, John Radcliffe Hospital, Headington, Oxford OX3 9DS, UK; ${ }^{3}$ Nuffield Department of Surgery, \\ University of Oxford, John Raddliffe Hospital, Headley Way, Headington, Oxford, OX3 9DU, UK; ${ }^{4}$ Regeneron Pharmaceuticals, 777 Old Saw Mill River \\ Road, Tarrytown, NY 059 I, USA; ${ }^{5}$ Department of Pathology, Peter MacCallum Cancer Centre, St Andrew's Place, East Melbourne, Victoria 3002, \\ Australia
}

BACKGROUND: Delta-like ligand 4 (DII4) is a Notch ligand that is upregulated by hypoxia and vascular endothelial growth factor-A (VEGF-A) and is reported to have a role in tumor angiogenesis. Evidence from xenograft studies suggests that inhibiting DII4-Notch signalling may overcome resistance to anti-VEGF therapy. The aim of this study was to characterise the expression of DII4 in colon cancer and to assess whether it is associated with markers of hypoxia and prognosis.

METHOD: In all, 177 colon cancers were represented in tissue microarrays. Immunohistochemistry was performed using validated antibodies against DII4, VEGF, hypoxia-inducible factor (HIF)- | $\alpha$, HIF-2 $\alpha$, prolyl hydroxylase (PHD)I, PHD2, PHD3 and carbonic anhydrase 9 (CA9).

RESULTS: The expression of DII4 was observed preferentially in the endothelium of 71\% ( 25 out of I75) of colon cancers, but not in the endothelium adjacent to normal mucosa (none out of I07, P<0.000 I). The expression of VEGF was significantly associated with HIF- $2 \alpha(P<0.000 \mathrm{I})$ and DII4 $(P=0.010)$. Only HIF-2 $\alpha$ had a significant multivariate prognostic effect (hazard ratio I.6I, 95\% confidence interval I.0I-2.57). Delta-like ligand 4 was also expressed by neoplastic cells, particularly neoplastic goblet cells.

CONCLUSION: Endothelial expression of DII4 is not a prognostic factor, but is significantly associated with VEGF. Assessing endothelial DII4 expression may be critical in predicting response to anti-VEGF therapies.

British Journal of Cancer (2009) I 01, 1749- 1757. doi:10.1038/sj.bjc.6605368 www.bjcancer.com

Published online 20 October 2009

(C) 2009 Cancer Research UK

Keywords: delta-like ligand 4; colon cancer; hypoxia; angiogenesis; survival

Colorectal cancer is the second most common cause of cancer deaths worldwide, with an estimated 1023152 new cases and 528978 related deaths in 2002(Parkin et al, 2005). The early growth of colorectal tumours requires angiogenesis (Goodlad et al, 2006; Korsisaari et al, 2007), the consequence of increased expression of pro-angiogenic factors (e.g., vascular endothelial growth factor-A (VEGF-A); Ferrara et al, 1991; Kim et al, 1993; Jubb et al, 2003; Korsisaari et al, 2007). The expression of VEGF in cancer is controlled by both oncogenic signalling (such as Wnt-signalling in colorectal cancer; Zhang et al, 2001) and hypoxia (Mizukami et al, 2004). Although there is redundancy among pro-angiogenic factors in advanced cancer (Relf et al, 1997; Hanrahan et al, 2003), many early cancers (Hanrahan et al, 2003; Jubb et al, 2003) and in vivo cancer models (Bergers et al, 1999; Hanrahan et al, 2003; Joyce et al, 2003; Goodlad et al, 2006; Korsisaari et al, 2007) are VEGF dependent. This observation has been exploited by the addition of an anti-VEGF monoclonal antibody (bevacizumab) to first-line

\footnotetext{
*Correspondence: Professor AL Harris; E-mail: aharris.lab@imm.ox.ac.uk ${ }^{6}$ These authors contributed equally to this work.

Received 23 June 2009; revised 4 September 2009; accepted 17 September 2009; published online 20 October 2009
}

chemotherapy in metastatic colorectal cancer, which prolonged the median overall survival (from 15.6 to 20.3 months, $P=0.001$; Hurwitz et al, 2004). Nevertheless, all patients in this trial eventually progressed after 2 years (Jubb et al, 2006b), and there are no valid predictors of the survival benefit afforded by bevacizumab in colorectal cancer (Ince et al, 2005; Jubb et al, 2006a; Grothey et al, 2008a, b).

Additional therapeutic agents that disrupt functional tumour angiogenesis have been developed to target tumours that are inherently resistant to anti-VEGF therapy or become resistant during the course of therapy (Noguera-Troise et al, 2006; Ridgway et al, 2006; Pan et al, 2007; Caunt et al, 2008). Delta-like Ligand 4 (Dll4) is a ligand for Notch 1, 3 and 4 proteins, which is expressed by endothelial cells (Thurston et al, 2007; Indraccolo et al, 2009) and may be induced by VEGF and hypoxia, through hypoxiainducible factor (HIF)-1 $\alpha$ (Patel et al, 2005). In the retina, the interaction between Dll4 and Notch regulates endothelial sprouting and branching to form functional vascular beds (Hellstrom et al, 2007). Disruption of Dll4 signalling by overexpression or inhibition of Dll4 may impair tumour angiogenesis (Noguera-Troise et al, 2006; Ridgway et al, 2006), and blockade of Dll4-Notch signalling results in an increased density of non-functional vasculature and is associated with a reduction in the growth of 
human xenografts (Noguera-Troise et al, 2006; Ridgway et al, 2006). Indeed, certain xenografts that are resistant to anti-VEGF therapy are reported to be sensitive to anti-Dll4 (Noguera-Troise et al, 2006; Ridgway et al, 2006; Li et al, 2007), and combination treatment with anti-VEGF and anti-Dll4 has additive effects on tumour growth (Ridgway et al, 2006). In addition, human umbilical vein endothelial cells transfected with Dll4 downregulate the VEGF receptor 2 and co-receptor neuropilin-1, and show reduced proliferative and migratory responses to VEGF (Williams et al, 2006). Together, these data suggest that Dll4 may have a role in mediating resistance to anti-VEGF therapies.

The characterisation of Dll4 protein expression in human cancer is important for the rational design of clinical trials to test the safety and activity of anti-Dll4 therapy. Moreover, defining the context of Dll4 expression, in terms of known markers of hypoxia and angiogenesis, may identify subgroups of tumours with distinct clinical behaviour and response to treatment. The aims of this study were to characterise the in situ expression of Dll4 in colon cancer, to assess the association between Dll4 and established markers of hypoxia and angiogenesis and to determine the prognostic significance of these markers.

\section{PATIENTS AND METHODS}

\section{Cell lines}

Recombinant human Dll4 was cloned into a pcDNA3.1 vector (Invitrogen, Carlsbad, CA, USA). Vectors were transfected into human U87 cells with the Fugene 6 transfection reagent (Roche Applied Science, Indianapolis, IN, USA). Human umbilical vein endothelial cells were cultured in vitro in media with and without VEGF as previously described (Harrington et al, 2007). Cell pellets were then formalin fixed and paraffin embedded. Further details are available from the authors on request.

\section{Patients and tissue samples}

Formalin-fixed and paraffin-embedded tissue blocks and corresponding pathology reports were retrospectively obtained for 177 sequential patients with colon adenocarcinomas (surgery was performed from 1997 to 2000 at the John Radcliffe Hospital, Oxford, UK). Sample size was determined by the availability of tissue with full clinicopathological data, survival follow-up and ethical approval for research. No patients received preoperative chemotherapy. Rectal cancers were excluded from this series to avoid the confounding effects that preoperative radiotherapy may have on the expression of hypoxic markers. The mean age at diagnosis was 71 years (range 17-92 years), 97 patients (55\%) were male and 73 cancers $(41 \%)$ were at or distal to the splenic flexure. In all, 13 cancers were in Dukes' stage A (7\%), 88 in stage B (50\%), 55 in stage $C(31 \%)$ and 21 in stage $D(12 \%)$ at the time of surgery. The mean follow-up time was 5.6 years (range 1 month to 11.9 years). No patients received postoperative radiotherapy. No Dukes' stage A patients, $38 \%$ (24 out of 64 ) of Dukes' stage B patients, $58 \%$ (32 out of 55) of Dukes' stage C patients and 52\% (11 out of 21) of Dukes' stage D patients received 5-fluorouracil-based chemotherapy according to the local protocols (adjuvant regimen: six 5-day

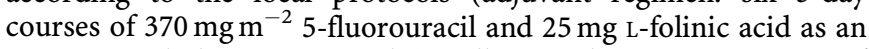
intravenous bolus every 4 weeks). Follow-up data were correct as of January 2009, with a median follow-up time of 5 years and 7 months. Tissue microarrays were assembled as described previously (Bubendorf et al, 2001) with three replicate cores for each tumour and one core for each normal mucosal sample. An additional 12 whole sections of colorectal adenomas with adjacent adenocarcinoma were also collected (John Radcliffe Hospital) to further analyse the expression of Dll4 in the adenoma to adenocarcinoma sequence. Approval was obtained for the use of all human tissue from the local research ethics committee (C02.216).

\section{In situ hybridisation}

Isotopic in situ hybridisation for Dll4 was performed using previously described methods (Poulsom et al, 1998). The probe used was a 741-bp cloned fragment of human Dll4 (position 1775 to $2516 \mathrm{bp}$, relative to the adenosine of the start codon ATG; Patel et al, 2006). In situ hybridisation for $\beta$-actin was used as a positive control for mRNA integrity.

\section{Immunohistochemistry}

Immunohistochemistry for VEGF (clone VG1; Turley et al, 1998; Boddy et al, 2005), HIF-1 $\alpha$ (clone 54, BD Transduction Laboratories, San Jose, CA, USA) (Wiesener et al, 2001), HIF-2 $\alpha$ (clone EP190/E10; Talks et al, 2000; Boddy et al, 2005), prolyl hydroxylase 1 (PHD1) (clone 112/E8), PHD2 (clone 366G/76/3), PHD3 (clone EG188e/E6) (Appelhoff et al, 2004; Boddy et al, 2005; Soilleux et al, 2005) and carbonic anhydrase 9 (CA9) (clone M75, a gift from Professors S Pastorekova and J Pastorek, Institute of Virology, Slovak Academy of Sciences, Bratislava, Slovak Republic) (Pastorekova et al, 1992; Loncaster et al, 2001) was performed using antibodies as previously described. Validation of all antibodies has been previously undertaken and published by our group using cells transfected with the relevant targets (see references listed above). Unless otherwise stated, all antibodies were made in the Nuffield Department of Clinical Laboratory Sciences at the University of Oxford, UK.

Immunohistochemistry for Dll4 was performed using an antiDll4 monoclonal antibody (the variable regions of this antibody are fully human and the Fc-domain is mouse; clone 242) that binds to the extracellular domain of human Dll4 (the epitope is in EGF-like domains 3-5 and generated in VelocImmune mice (Regeneron Pharmaceuticals, Inc., Tarrytown, NY, USA)). In brief, antigen retrieval was performed in target retrieval solution (Dako, Carpinteria, CA, USA) using a Decloaking Chamber (Biocare Medical, Concord, CA, USA). Sections were incubated for $16 \mathrm{~h}$ at $4{ }^{\circ} \mathrm{C}$ with the primary antibody at $1 \mu \mathrm{g} \mathrm{ml}^{-1}$. Bound antibody was labeled with Novolink polymer (Leica Microsystems, Bannockburn, IL, USA), visualised using 2,3-diaminobenzidine chromogen and counterstained with hematoxylin. Control sections of bladder cancer and normal kidney were included to assess the specificity of the antibody.

Staining for HIF- $1 \alpha$ and HIF- $2 \alpha$ was scored positive if expression was observed in any epithelial cell nuclei. Cores were scored positive for CA9 if membranous expression was observed in $>10 \%$ of epithelial cells. Staining for VEGF, PHD1, PHD2 or PHD3 was scored positive if cytoplasmic expression was observed in $>10 \%$ of epithelial cells. Cores were scored positive for Dll4 if expression was observed in any endothelial cells. In addition, Dll4 was scored in the neoplastic cells within TMA cores in which it was observed at high levels, that is, levels that approximated the intensity of Dll4 expression by endothelial cells. The highest intensity score among replicate cores was used as the score for each patient. Assays and scoring were performed blind to clinical and pathological data (withheld for analysis until all data were complete).

\section{Statistics}

The $\chi^{2}$ test was used to evaluate associations between categorical variables. The Student's $t$-test was used to evaluate associations between continuous and categorical variables. The Benjamini and Hochberg false discovery rate controlling procedure was used to eliminate spurious statistical associations as a result of multiple testing (Benjamini and Hochberg, 1995). All survival analyses refer to overall survival times, in which death from any cause represents an event. Marker values were assessed as ordinal categorical data in survival analyses. Median overall survival times within each subgroup were estimated from Kaplan-Meier curves. Patients were censored in survival analyses according to the date last seen by a doctor. The log-rank (Mantel-Cox) test was used to assess the 
significance of univariate survival analyses. For multivariate survival models, a Cox regression analysis was used to identify independent prognostic factors. All statistical analyses were carried out using SPSS Statistics (version 16.0, SPSS, Chicago, IL, USA). The two-sided $P$-values of $<0.05$ were considered statistically significant. Cases with missing data were omitted from statistical analyses.

\section{Reporting recommendations for tumour marker prognostic studies (REMARK) criteria}

The REMARK criteria of the National Cancer Institute were used in the design, analysis and interpretation of this research (McShane et al, 2005).

\section{RESULTS}

\section{Frequency and pattern of expression of hypoxia-regulated proteins}

Analyses of tumours from the 177 patients yielded informative data on 155 to 177 patients. Results were not available for the remaining cases in certain assays because of the limited amounts of tissue represented in the tissue microarrays.

In all, $39 \%$ (60 out of 155 ) and $53 \%$ (85 out of 159 ) of colon cancers were positive for nuclear HIF- $1 \alpha$ and HIF- $2 \alpha$ expression, respectively; $21 \%$ of cases (31 out of 147) expressed both HIF- $1 \alpha$ and HIF- $2 \alpha$ and $51 \%$ of cases (75 out of 147) expressed either HIF- $1 \alpha$ or HIF- $2 \alpha$. In addition, HIF- $1 \alpha$ expression was only observed in cell nuclei when present (Figure 1A), as previously described (Jubb et al, 2004). The expression of HIF- $2 \alpha$ by neoplastic cells was predominantly cytoplasmic, with nuclear expression in a proportion of cases (Figure 1B; Talks et al, 2000). The expression of HIF- $2 \alpha$ was also observed in a proportion of infiltrating inflammatory cells as previously reported (Talks et al, 2000), although these data were not specifically recorded. The expression of VEGF was observed in the cytoplasm of neoplastic cells $(88 \%, 149$ out of 169$)$, stromal fibroblasts, inflammatory cells, endothelial cells and the extracellular matrix (Figure 1C), as previously reported (Jubb et al, 2006a).

The PHD family of HIF-regulatory proteins is expressed in the cytoplasm of the majority of colon cancers (Figures 1D-F), similar to prostate cancer (Boddy et al, 2005). Prolyl hydroxylase 1 was present in $72 \%(116 / 162)$, PHD2 in 82\% (135/164) and PHD3 in
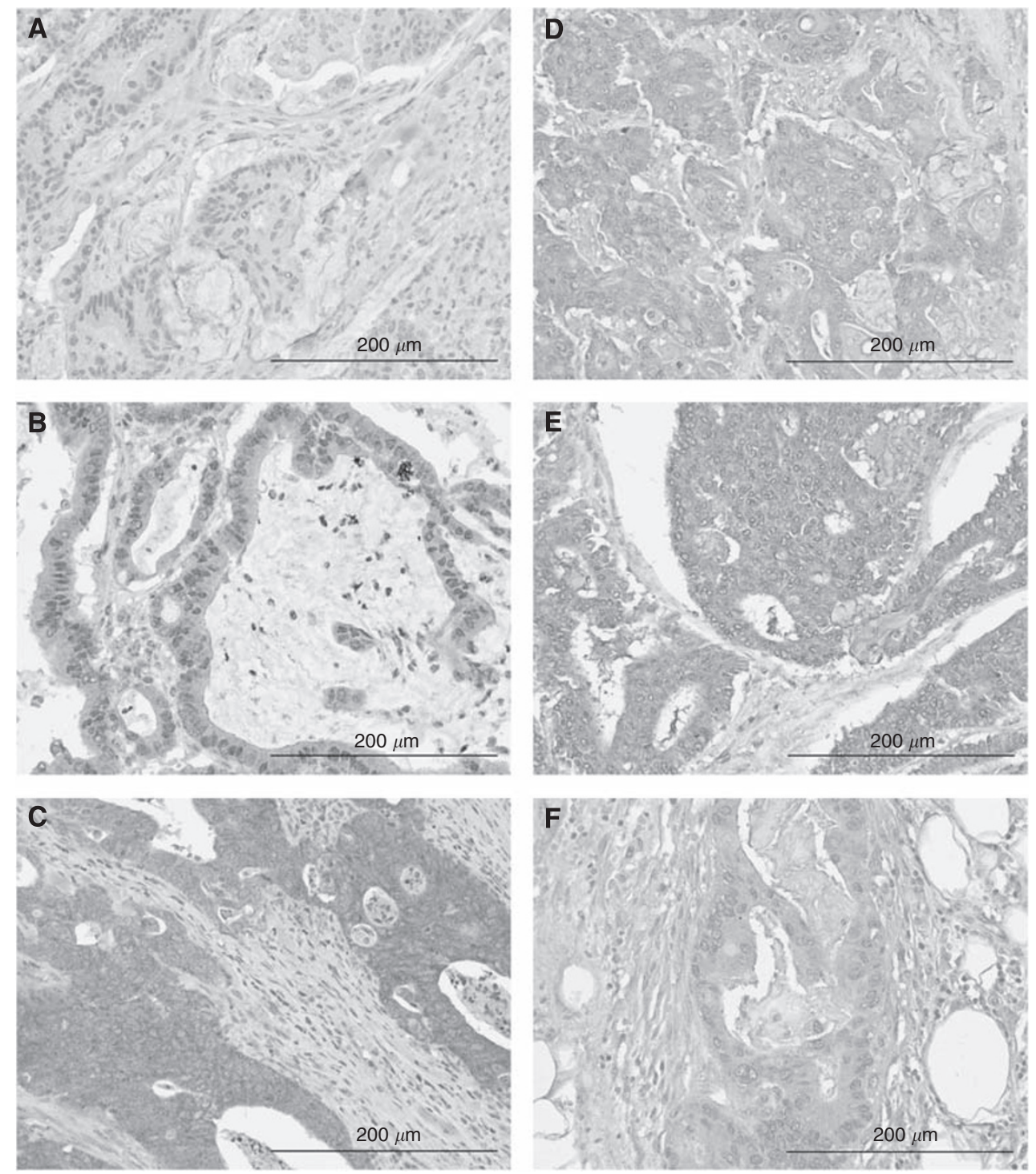

Figure I Representative examples of immunohistochemistry in colon cancer showing nuclear HIF- $\mid \alpha(\mathbf{A})$ and $H I F-2 \alpha(\mathbf{B})$ expression, and cytoplasmic VEGF (C), PHDI (D), PHD2 (E) and PHD3 (F) expression. 
$70 \%(120 / 172)$ of colon cancers. Similarly, the majority of colon cancers show strong membranous expression of the HIF-1 target gene CA9 (67\%, 110/165; Figure 2A), consistent with other series (Rasheed et al, 2009).

\section{Validation of the anti-Dll4 antibody}

The human monoclonal antibody (clone 242) that specifically recognises the extracellular domain of human Dll4 did not stain U87 cells transiently transfected with empty vector (Supplementary Figure 1A), but showed membranous and cytoplasmic staining in U87 cells transiently transfected with the recombinant human Dll4 full-length gene (Supplementary Figure 1B). Human umbilical vein endothelial cells showed immunoreactivity for Dll4 that was greater in intensity when cells were treated with VEGF (Supplementary Figures 1C and D). Normal kidney did not express Dll4, but endothelial cells in renal cell carcinoma showed endothelial expression of Dll4, consistent with previous in situ hybridisation results (Supplementary Figures $1 \mathrm{E}$ and F) (Patel et al, 2005). Serial sections of bladder cancer showed endothelial colocalisation of Dll4 mRNA using in situ hybridisation (Patel et $a l, 2006$ ), and protein using immunohistochemistry (Supplementary Figures $1 \mathrm{D}-\mathrm{F}$ ).

\section{Frequency and pattern of expression of Dll4}

In $71 \%$ (125 out of 175) of colon cancer tissues analysed, Dll4 expression was observed in the cytoplasm of the endothelial cells lining vessels adjacent to cancer (Figure 2B). Membranous localisation of Dll4 was difficult to differentiate from cytoplasmic localisation because of the slender nature of endothelial cytoplasmic processes. The expression of Dll4 was only rarely observed in the endothelial lining of large vessels around or into which cancer cells had invaded. In the whole sections of colorectal adenomas with adjacent adenocarcinoma, Dll4 was observed at identical frequencies in the endothelium found in both the adenomas and
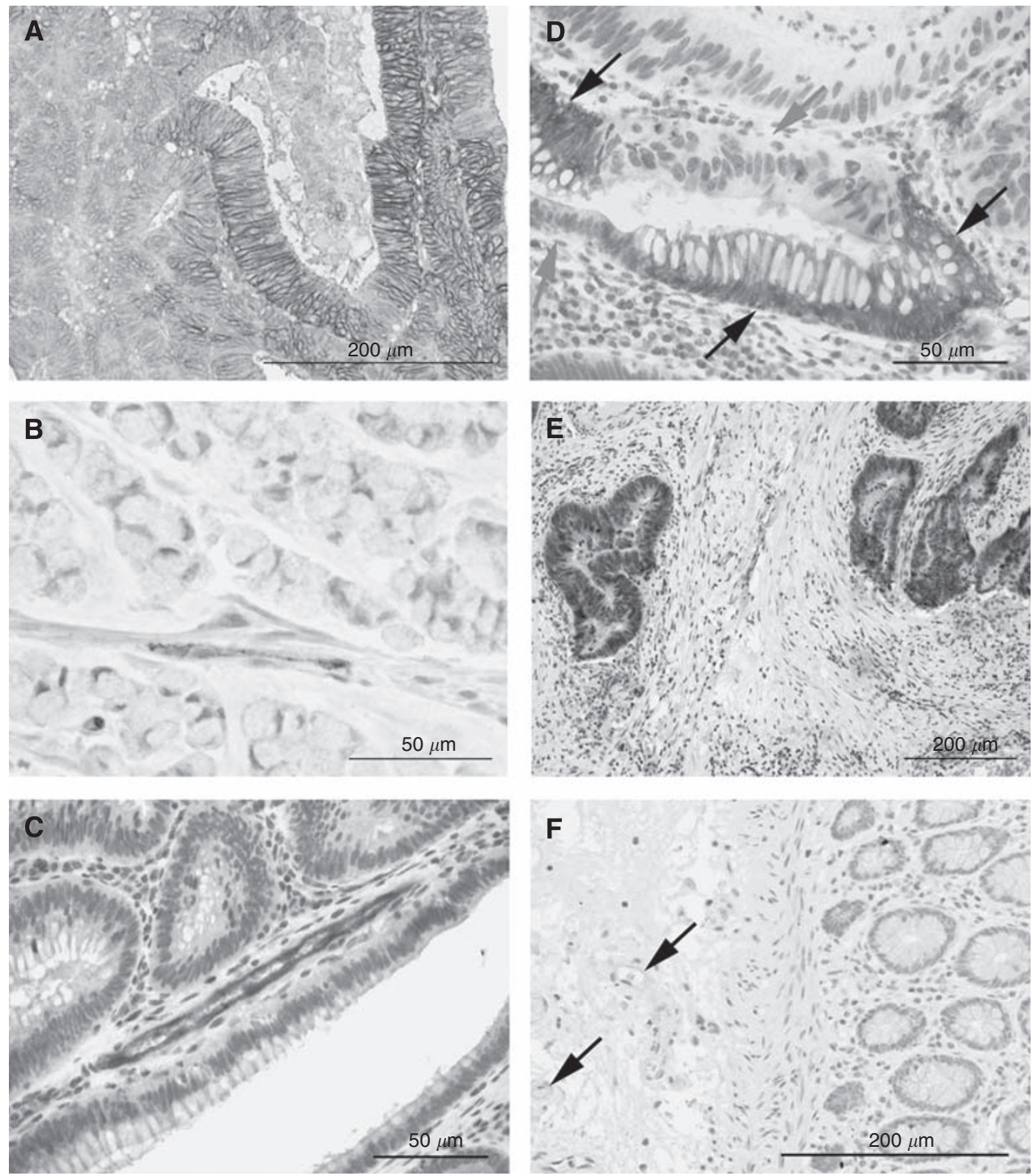

Figure 2 Representative examples of immunohistochemistry in colon cancer showing membranous CA9 adjacent necrosis (A) and endothelial DII4 (B) expression. Immunohistochemistry for Dll4 shows membranous and cytoplasmic endothelial expression in a colon adenoma (C) and epithelial expression associated with goblet cell differentiation in a neoplastic crypt ((D) black arrows indicate Dll4-positive goblet cells, and red arrows indicate DII4-negative non-goblet cells). DII4 is also weakly expressed by neoplastic cells without goblet cell differentiation in a colon adenocarcinoma (E). Endothelial cells lining vessels (arrows) adjacent to normal colonic crypts did not express Dll4 by immunohistochemistry $(\mathbf{F})$. 
adenocarcinomas (12 out of 12, Figure 2C, Supplementary Figures $2 \mathrm{~A}-\mathrm{C})$. The endothelium associated with colonic adenomas and adenocarcinomas (i.e., within two low-power fields of the tumour cells) was positive for Dll4 in $60-100 \%$ of vessels (identified by CD34 immunoreactivity in serial sections, data not shown). Similar levels of endothelial Dll4 expression were observed in the centre of the tumour and at the invading edge. In all, 16\% (28 out of 177) of colon cancers represented in the tissue microarrays expressed levels of Dll4 in the cytoplasm and membrane of neoplastic cells that approximated the intensity of expression observed in endothelium. In the whole sections, $>10 \%$ of the malignant epithelial cells of the colorectal adenomas and adjacent adenocarcinomas expressed Dll4 in 8 of 12 cases (median 30\%, range $10-60 \%)$. In regions of both colorectal adenomas and adenocarcinomas, high levels of Dll4 expression were observed in neoplastic epithelial cells with goblet cell differentiation (Figure 2D, Supplementary Figure 2D). (Goblet cells were defined morphologically.) Elsewhere, Dll4 was expressed at a lower level by neoplastic cells without goblet cell morphology (Figure 2E). Endothelial cells adjacent to normal colon mucosa distant from cancer did not express Dll4 protein (0 out of 107). Epithelial cells lining normal colonic crypts, irrespective of their morphology, did not express Dll4 (Figure 2F), although occasional cells in the superficial surface mucosa of normal colon stained weakly for Dll4 (data not shown). Specifically, normal colonic goblet cells did not express Dll4. The pattern of Dll4 expression by in situ hybridisation matched the immunohistochemistry results for the 12 colorectal adenomas with adjacent adenocarcinoma (Supplementary Figure 3).

\section{Associations between molecular and pathological variables}

Hypoxia-inducible factor- $1 \alpha$ and CA9 were not significantly associated with any other immunohistochemical markers in colon cancer (Table 1 ). In contrast, HIF- $2 \alpha$ was significantly associated with VEGF, Dll4, PHD1, PHD2 and PHD3. Vascular endothelial growth factor was significantly associated with endothelial Dll4, PHD1, PHD2 and PHD3. Endothelial Dll4 was also significantly associated with PHD1 and PHD3. Prolyl hydroxylase (PHD)1, PHD2 and PHD3 were significantly associated with each other. In addition, endothelial expression of Dll4 was negatively associated with nuclear HIF- $2 \alpha$ expression by tumour cells, but this association was not significant after correction for multiple testing. Delta-like ligand 4 expression by malignant epithelial cells was not associated with any clinicopathological or molecular variables (data not shown).

None of the immunohistochemical markers analysed in this study were associated with tumour stage, lymphatic invasion, vascular invasion, grade, sex or site after the false discovery rate controlling procedure was used to exclude spurious results (Table 2). Similarly, no immunohistochemical markers were associated with age using the Student's $t$-test (data not shown).

\section{Survival}

In univariate analyses, only nuclear HIF- $2 \alpha(P=0.027)$, pT stage $(P=0.0003)$, pN stage $(P<0.0001)$, M stage $(P<0.0001)$, lymphatic invasion $(P=0.007)$, vascular invasion $(P=0.002)$, grade $(P=0.028)$ and adjuvant chemotherapy $(P=0.003)$ significantly correlated with overall survival (Table 3, Figure 3 ). (Note that the patients receiving adjuvant chemotherapy seem to have performed worse in overall survival analyses as they disproportionately represent advanced-stage cancers). The relationship between age and overall survival was assessed using Cox regression; it was not statistically significant, $P=0.10$. Patients with cancers that were positive for nuclear HIF- $2 \alpha$ expression had a significantly shorter median survival (57 months, 95\% confidence interval 36-79 months) than patients with cancers that were negative for nuclear HIF- $2 \alpha$ expression (101 months, 95\% confidence interval 81-121
Table I Statistical significance of associations between molecular variables

\begin{tabular}{|c|c|c|c|c|c|c|c|}
\hline Variable & HIF- $2 \alpha$ & CA9 & VEGF & $\begin{array}{c}\text { Dll4 } \\
\text { Endo. }\end{array}$ & PHDI & PHD2 & PHD3 \\
\hline HIF-I $\mid \alpha \chi^{2}$ & $<0.01$ & 3.43 & 0.96 & 2.08 & 0.23 & $<0.01$ & $<0.01$ \\
\hline$P$ & 1.00 & 0.09 & 0.33 & 0.11 & 0.63 & 0.97 & 1.00 \\
\hline HIF- $2 \alpha \chi^{2}$ & - & $<0.01$ & 18.78 & 4.5 & 4.24 & $10.4 \mid$ & 11.75 \\
\hline $\begin{array}{ll} & P \\
\text { CA9 } & \chi^{2} \\
& P\end{array}$ & - & 0.96 & $\begin{array}{l}<0.0001 \\
<0.01 \\
\mid 00\end{array}$ & $\begin{aligned} & 0.03 * 3^{* a} \\
&< 0.01 \\
& 1.00\end{aligned}$ & $\begin{array}{l}0.04 * \\
1.45 \\
0.23\end{array}$ & $\begin{array}{l}0.001 \\
4.53 \\
0.03 *\end{array}$ & $\begin{array}{c}<0.001 \\
1.11 \\
0.29\end{array}$ \\
\hline$\chi^{2}$ & - & - & - & $\begin{array}{l}5.98 \\
0.01\end{array}$ & $\begin{array}{l}34.15 \\
<0.0001\end{array}$ & $\begin{array}{l}25.33 \\
<0.000 \text { I }\end{array}$ & $\begin{array}{l}29.92 \\
<0.0001\end{array}$ \\
\hline $\begin{array}{ll}\text { Dll4 } & \chi^{2} \\
\text { Endo. } & \end{array}$ & - & - & - & - & 5.43 & 0.26 & 7.14 \\
\hline $\begin{array}{ll} & P \\
\text { PHDI } & \chi^{2} \\
& P\end{array}$ & - & - & - & - & $\begin{array}{l}0.01 \\
-\end{array}$ & $\begin{array}{c}0.61 \\
\mid 6.04 \\
<0.000 \mid\end{array}$ & $\begin{array}{l}0.008 \\
32.90 \\
<0.0001\end{array}$ \\
\hline $\begin{array}{ll}\text { PHD2 } & \chi^{2} \\
& P\end{array}$ & - & - & - & - & - & - & $\begin{array}{l}13.85 \\
0.0002\end{array}$ \\
\hline
\end{tabular}

${ }^{a}$ Negative association. All associations are positive unless otherwise stated. *These $P$-values are not significant after correction for multiple testing by the Benjamini and Hochberg false discovery rate controlling procedure with a cutoff $=0.05$. Abbreviations: Endo. = endothelial; PHDI = prolyl hydroxylase; VEGF = vascular endothelial growth factor; $\mathrm{CA} 9=$ carbonic anhydrase 9; HIF=hypoxia-inducible factor; D\|4 = delta-like ligand 4.

Table 2 Statistical significance of associations between molecular and categorical clinical variables

\begin{tabular}{lllllllllll}
\hline Variable & $\mathbf{p T}$ & $\mathbf{p N}$ & $\mathbf{M}$ & $\mathbf{L I}$ & $\mathbf{V I}$ & Grade & Sex & Site & $\mathbf{A C}$ \\
\hline HIF-I $\alpha$ & $\chi^{2}$ & 1.37 & 2.97 & 0.25 & $<0.01$ & 1.37 & 6.26 & 0.18 & 5.55 & 1.10 \\
& $P$ & 0.71 & 0.40 & 0.62 & 0.94 & 0.24 & $0.04 *$ & 0.67 & $0.02 *$ & 0.29 \\
HIF-2 $\alpha$ & $\chi^{2}$ & 1.08 & 0.37 & 2.87 & 0.24 & 0.49 & 1.79 & 0.03 & 3.64 & 0.45 \\
& $P$ & 0.78 & 0.95 & 0.09 & 0.62 & 0.49 & 0.41 & 0.88 & 0.06 & 0.50 \\
CA9 & $\chi^{2}$ & 2.39 & 4.22 & 0.12 & 0.90 & 0.76 & 2.25 & 0.89 & 4.09 & 0.00 \\
& $P$ & 0.50 & 0.24 & 0.73 & 0.34 & 0.38 & 0.33 & 0.27 & $0.04 *$ & 1.00 \\
VEGF & $\chi^{2}$ & 2.00 & 7.77 & 0.89 & 0.10 & 0.49 & 1.90 & 0.82 & 4.07 & 0.00 \\
& $P$ & 0.57 & 0.05 & 0.35 & 0.75 & 0.49 & 0.39 & 0.37 & $0.04 *$ & 1.00 \\
DII4 & $\chi^{2}$ & 0.40 & 1.77 & $<0.01$ & 0.13 & 0.07 & 0.44 & 0.92 & 0.06 & 0.05 \\
Endo. & $P$ & 0.94 & 0.62 & 1.00 & 0.72 & 0.79 & 0.80 & 0.34 & 0.81 & 0.83 \\
PHDI & $\chi^{2}$ & 9.18 & 3.28 & 0.13 & 0.30 & 0.26 & 9.61 & 0.25 & $<0.01$ & 0.00 \\
& $P$ & $0.03 *$ & 0.35 & 0.72 & 0.58 & 0.61 & $0.01 *$ & 0.62 & 0.93 & 1.00 \\
PHD2 & $\chi^{2}$ & 1.83 & 0.99 & 2.28 & 1.09 & 0.11 & 1.05 & 0.12 & 3.80 & 0.00 \\
& $P$ & 0.61 & 0.80 & 0.13 & 0.30 & 0.74 & 0.59 & 0.91 & 0.05 & 1.00 \\
PHD3 & $\chi^{2}$ & 2.30 & 3.31 & $<0.01$ & 0.60 & 1.43 & 5.99 & 1.43 & 0.80 & 0.09 \\
& $P$ & 0.51 & 0.35 & 0.98 & 0.44 & 0.23 & 0.05 & 0.23 & 0.78 & 0.77 \\
& & & &
\end{tabular}

Abbreviations: $A C=$ adjuvant chemotherapy; Endo. = endothelial; $\mathrm{LI}=$ lymphatic invasion; $\quad \mathrm{VI}=$ vascular invasion; $\mathrm{PHD}=$ prolyl hydroxylase; $\mathrm{VEGF}=$ vascular endothelial growth factor; CA9= carbonic anhydrase 9; HIF=hypoxia-inducible factor; $\mathrm{D} \| 4=$ delta-like ligand 4 . *These $P$-values are not significant after correction for multiple testing by the Benjamini and Hochberg false discovery rate controlling procedure 40 with a cutoff $=0.05$

months). In addition, HIF- $2 \alpha$ showed statistical significance $(P=0.044)$ in multivariate survival analyses (Table 4). The Cox regression multivariate survival model also included $\mathrm{pT}$ stage $(P<0.05)$, pN stage $(P=0.009), \mathrm{M}$ stage $(P<0.0001)$, lymphatic invasion $(P=0.32)$, vascular invasion $(P=0.48)$, grade $(P=0.56)$ and adjuvant chemotherapy $(P=0.56)$ (Table 4$)$. The significance of statistical associations and survival analyses does not differ if the intensity of staining of the immunohistochemical markers was scored on a semiquantitative scale, as opposed to positive or negative (data not shown).

Endothelial Dll4 expression was not a statistically significant prognostic factor (Table 3). Although these are exploratory analyses, power calculations for Dll4 showed a statistical power 
Table 3 Univariate analysis of overall survival

\begin{tabular}{|c|c|c|c|c|c|}
\hline Variable & $N$ & Events & $\begin{array}{c}\text { Median } \\
\text { survival } \\
\text { (months) }\end{array}$ & $\begin{array}{l}95 \% \text { Confidence } \\
\text { interval (months) }\end{array}$ & $P$-value ${ }^{a}$ \\
\hline $\begin{array}{l}\text { Overall } \\
H I F-1 \alpha\end{array}$ & 177 & 102 & 83.3 & $58.9-107.7$ & \\
\hline Negative & 95 & 56 & 79.6 & $45.5-113.7$ & \\
\hline Positive & 60 & 38 & 77.6 & $40.8-114.4$ & 0.91 \\
\hline \multicolumn{6}{|l|}{$H I F-2 \alpha$} \\
\hline Negative & 74 & 37 & 101.5 & $81.5-120.7$ & \\
\hline Positive & 85 & 55 & 57.4 & $36.1-78.7$ & 0.027 \\
\hline \multicolumn{6}{|l|}{ CA9 } \\
\hline Negative & 55 & 32 & 79.6 & $30.2-128.9$ & \\
\hline Positive & 110 & 66 & 79.1 & $48.1-110.1$ & 0.87 \\
\hline \multicolumn{6}{|l|}{ VEGF } \\
\hline Negative & 20 & 10 & 83.3 & $72.6-94.0$ & \\
\hline Positive & 149 & 88 & 79.6 & $49.2-110.0$ & 0.46 \\
\hline \multicolumn{6}{|l|}{ Dll4 Endo. } \\
\hline Negative & 50 & 29 & 64.0 & $9.0-118.0$ & \\
\hline Positive & 125 & 72 & 89.0 & $64.2-113.6$ & 0.94 \\
\hline \multicolumn{6}{|l|}{ PHDI } \\
\hline Negative & 46 & 26 & 79.1 & $46.0-112.2$ & \\
\hline Positive & 116 & 69 & 88.9 & $56.2-121.6$ & 0.71 \\
\hline \multicolumn{6}{|l|}{ PHD2 } \\
\hline Negative & 29 & 13 & 111.5 & $N R$ & \\
\hline Positive & 135 & 83 & 66.7 & $37.7-95.7$ & 0.08 \\
\hline \multicolumn{6}{|l|}{ PHD3 } \\
\hline Negative & 52 & 29 & 97.8 & $68.2-127.4$ & \\
\hline Positive & 120 & 70 & 68.9 & $39.9-97.8$ & 0.67 \\
\hline \multicolumn{6}{|l|}{ pT stage } \\
\hline 1 & 5 & 2 & NR & & \\
\hline 2 & 13 & 4 & $N R$ & & \\
\hline 3 & 77 & 37 & 110.9 & $97.9-124.0$ & \\
\hline 4 & 82 & 59 & 45.0 & $32.4-57.6$ & 0.0003 \\
\hline \multicolumn{6}{|l|}{ pN stage } \\
\hline 0 & 103 & 45 & 139.9 & $98.1-181.7$ & \\
\hline 1 & 43 & 31 & 49.2 & $25.6-72.7$ & \\
\hline 2 & 28 & 24 & 18.1 & $1.8-34.3$ & \\
\hline 3 & 3 & 2 & 21.1 & $0-43.8$ & $<0.0001$ \\
\hline \multicolumn{6}{|l|}{ M stage } \\
\hline 0 & 156 & 82 & 100.0 & $82.1-118.0$ & \\
\hline I & 21 & 20 & 9.2 & $5.1-13.3$ & $<0.0001$ \\
\hline \multicolumn{6}{|l|}{ LI } \\
\hline Absent & 150 & 84 & 91.9 & $71.2-112.6$ & \\
\hline Present & 22 & 16 & 18.0 & $3.6-32.5$ & 0.007 \\
\hline \multicolumn{6}{|l|}{ VI } \\
\hline Absent & 131 & 70 & 97.6 & $73.6-121.7$ & \\
\hline Present & 41 & 30 & 23.1 & $0-52.4$ & 0.002 \\
\hline \multicolumn{6}{|l|}{ Grade } \\
\hline Good & 46 & 22 & 111.0 & $94.9-127.1$ & \\
\hline Moderate & 101 & 64 & 64.0 & $34.1-93.9$ & \\
\hline Poor & 11 & 8 & 28.9 & $0-83.5$ & 0.028 \\
\hline \multicolumn{6}{|l|}{ Sex } \\
\hline Female & 80 & 45 & 88.9 & $61.6-116.2$ & \\
\hline Male & 97 & 57 & 79.6 & $40.3-118.8$ & 0.68 \\
\hline \multicolumn{6}{|l|}{ Site } \\
\hline Distal & 73 & 45 & 77.6 & $41.7-113.5$ & \\
\hline Proximal & 104 & 57 & 88.9 & $57.7-120.0$ & 0.50 \\
\hline
\end{tabular}

Table 3 (Continued)

\begin{tabular}{lccccc}
\hline Variable & $\mathbf{N}$ & Events & $\begin{array}{c}\text { Median } \\
\text { survival } \\
\text { (months) }\end{array}$ & $\begin{array}{c}\text { 95\% Confidence } \\
\text { interval (months) }\end{array}$ & $\boldsymbol{P}_{\text {-value }}$ \\
\hline AC & & & & & \\
No & 110 & 56 & 101.1 & $82.5-119.7$ & \\
Yes & 67 & 46 & 54.4 & $41.0-67.8$ & 0.003 \\
\hline
\end{tabular}

Abbreviations: $\quad \mathrm{AC}=$ adjuvant chemotherapy; Endo. = endothelial; $\mathrm{LI}=$ lymphatic invasion; $N R=$ not reached; $\mathrm{Vl}=$ vascular invasion; $\mathrm{PHD}=$ prolyl hydroxylase: VEGF = vascular endothelial growth factor, $C A 9=$ carbonic anhydrase 9;

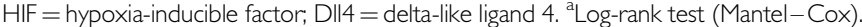

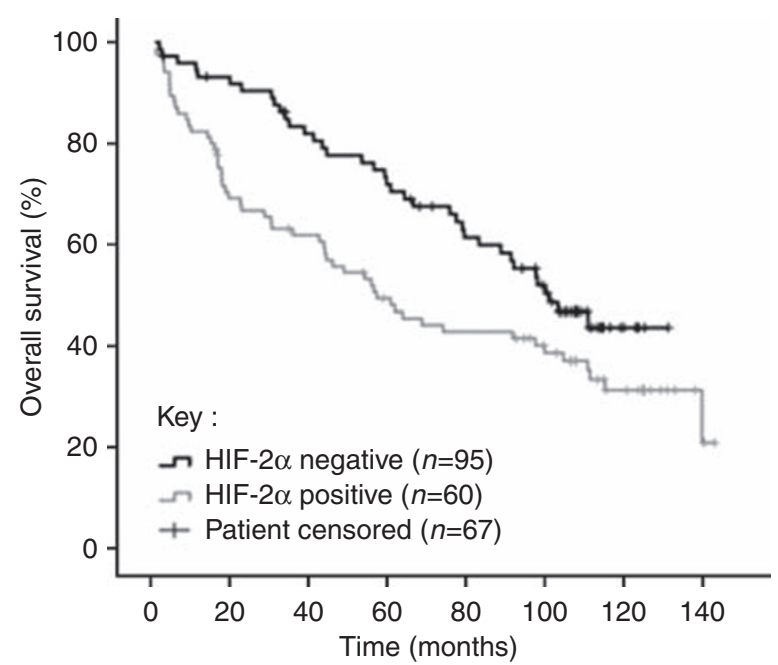

Figure 3 Kaplan-Meier survival curves for colon cancer patients subgrouped according to HIF- $2 \alpha$ expression. The patients with cancers who are positive for HIF- $2 \alpha$ have a significantly shorter median survival (57 months, 95\% confidence interval 36-79 months) than patients with cancers who are negative for HIF- $2 \alpha$ (I0I months, 95\% confidence interval $81-121$ months), $P=0.027$.

Table 4 Multivariate analysis of overall survival

\begin{tabular}{lcclc}
\hline Variable & $\begin{array}{c}\text { Hazard } \\
\text { ratio }\end{array}$ & $\begin{array}{c}\mathbf{9 5 \%} \text { Confidence } \\
\text { interval }\end{array}$ & $\begin{array}{l}\text { Association with } \\
\text { shorter survival }\end{array}$ & $\boldsymbol{P}_{\text {-value }}$ \\
\hline HIF-2 $\alpha$ & 1.61 & $1.01-2.57$ & Positive & 0.04 \\
PT stage & 1.46 & $1.00-2.13$ & High PT & $<0.05$ \\
PN stage & 1.60 & $1.13-2.26$ & High pN & 0.009 \\
M stage & 5.19 & $2.65-10.14$ & Present & $<0.0001$ \\
LI & 1.42 & $0.72-2.81$ & & 0.32 \\
VI & 1.23 & $0.69-2.20$ & & 0.48 \\
Grade & 1.14 & $0.73-1.80$ & & 0.56 \\
AC & 1.17 & $0.68-2.02$ & & 0.56 \\
\hline
\end{tabular}

Abbreviations: $A C=$ adjuvant chemotherapy; $\mathrm{LI}=$ lymphatic invasion; $\mathrm{VI}=$ vascular invasion; $\mathrm{HIF}=$ hypoxia-inducible factor. ${ }^{\mathrm{a}} \mathrm{Cox}$ regression

of 0.882 and a hazard ratio of 0.5 for control subjects versus experimental subjects (based on a type 1 error probability of 0.05 , an experimental group size of $n=50$, a control group size of $n=125$, an accrual time of 3 years, with 5 -year follow-up and a median survival time of 6.94 years; Dupont and Plummer, 1990).

\section{DISCUSSION}

Spatial regulation of an appropriate level of Dll4 expression is important in the development of a functional vasculature during 
physiological and pathological angiogenesis (Duarte et al, 2004; Noguera-Troise et al, 2006; Ridgway et al, 2006). Moreover, Dll4 expression may influence the sensitivity of endothelial cells to anti-VEGF therapy, with potential implications for the use of bevacizumab and novel anti-Dll4 antibodies in colorectal cancer (Noguera-Troise et al, 2006; Ridgway et al, 2006; Williams et al, 2006; Li et al, 2007). This is the first study to perform a detailed evaluation of Dll4 expression in colon cancer, and to relate Dll4 expression to other known histological and prognostic markers.

In this series of colon cancers, Dll4 expression was observed in the cytoplasm of the endothelium lining small vessels of neoplastic, but not normal tissue. This is consistent with data from human xenografts (Noguera-Troise et al, 2006) and in situ hybridisation data for Dll4 in human bladder cancer (Patel et al, 2006) and human renal cell carcinoma (Mailhos et al, 2001; Patel et al, 2005). The lack of expression of Dll4 in the endothelial cells and epithelium of normal colonic crypts is consistent with the lack of VEGF expression by normal colorectal mucosa (Jubb et al, 2003) and the lack of intestinal toxicity and goblet cell hyperplasia observed in anti-Dll4-treated mice (Ridgway et al, 2006). These data suggest that strategies targeting Dll4-Notch signalling may selectively affect the immature developing endothelium associated with colon cancer, but not endothelium associated with normal colonic mucosa or normal colonic crypt epithelium.

The observation of Dll4 expression by neoplastic crypts and the association with goblet cell morphology in colon adenomas and adenocarcinomas is novel. However, a report by van Es et al (2005) claims that inhibiting Notch signalling in the mouse intestine favours goblet cell differentiation in the proliferating cells of intestinal adenomas. Together with findings presented in this study, this suggests that both forward and reverse Notch signalling interact to define goblet cell differentiation in proliferating intestinal epithelium. The available data do not shed further light on the precise roles of Dll4 and its Notch receptors in the differentiation of goblet cells. Nevertheless, it is conceivable that manipulating Dll4-Notch signalling may have therapeutic relevance to colon cancer progression.

Activity of the hypoxia-inducible transcription factor isoforms, HIF-1 and HIF-2, is controlled by turnover of their $\alpha$-subunits, HIF- $1 \alpha$ and HIF- $2 \alpha$, respectively (Appelhoff et al, 2004). The data show that both HIF- $1 \alpha$ and HIF- $\alpha$ are expressed at similar frequencies in colon cancer. However, it was HIF-2 $\alpha$ that significantly associated with VEGF expression, suggesting that the hypoxic induction of VEGF is predominantly controlled by HIF- $2 \alpha$ in colon cancer. This is consistent with data by Mizukami et al (2004) who suggest that VEGF is induced in hypoxic regions of colorectal cancer by an HIF- $1 \alpha$-independent mechanism. Indeed, data from Knowles et al (2003) suggest that the availability of factors, such as oxygen, ascorbate and iron, may regulate which HIF isoform is active, even when both HIF-1 and HIF-2 are expressed. Therefore, it is possible that the microenvironment of colorectal cancer favours the activity of HIF-2 over HIF-1. Carbonic anhydrase 9 is predominantly regulated by HIF1 (not HIF-2) activity (Sowter et al, 2003), but does not significantly associate with HIF- $1 \alpha$ expression in colon cancer. This may be due to the confounding effects of the reported HIF-1independent induction of CA9 by hypoxia (Kaluz et al, 2002). The positive association between endothelial Dll4 and epithelial VEGF in colon cancer, observed in this study, is also consistent with data from model systems in which Dll4 expression by endothelial cells is reported to be regulated by VEGF (Patel et al, 2005). Together, these data suggest that, in colon cancer, VEGF expression may be regulated by HIF-2 activity and the expression of VEGF may induce Dll4 expression in adjacent endothelial cells. This is consistent with data reported by Skuli et al (2009) who show that the deletion of HIF- $2 \alpha$ in immortalised endothelial cells results in the downregulation of Dll4 expression.
The activity of HIF-1 and HIF-2 is reported to be regulated by hydroxylation of their $\alpha$-subunits by the PHD family members (Appelhoff et al, 2004). The hydroxylation is believed to target the HIF-1 and HIF- $2 \alpha$-subunits for destruction by the Von HippelLindau tumour suppressor protein (Appelhoff et al, 2004). In this study the expression of the PHD proteins was strongly associated with each other, consistent with data in prostate cancer (Boddy et al, 2005), and suggesting that they are regulated by a common mechanism. Expression of the PHD proteins did not significantly associate with HIF- $1 \alpha$, consistent with studies in prostate cancer (Boddy et al, 2005), but were also unexpectedly positively associated with HIF- $2 \alpha$. The reasons for this are not clear, but suggest that the role of the PHD proteins under model physiological conditions may be different to their role in cancer. However, PHD2 and PHD3 are targets of HIFs and are induced by hypoxia (Appelhoff et al, 2004), which may explain the paradoxical association, which limits the HIF effects in a well-recognised feedback loop (D'Angelo et al, 2003). Alternatively, other factors may regulate HIF- $2 \alpha$ expression in colon cancer, such as irondeficiency anemia (Sanchez et al, 2007), confounding the data. Further work is needed to analyse the role of the PHD proteins in regulating HIF-1 and HIF-2 activity in human neoplasia.

In survival analyses, the absence of an observed prognostic association for HIF- $1 \alpha$ in colon cancer is consistent with previous reports (Yoshimura et al, 2004). Moreover, the lack of a prognostic association for endothelial Dll4, a VEGF target (Patel et al, 2005), is in agreement with the lack of a prognostic association for VEGF in colon cancer in this study and elsewhere (Nanni et al, 2002; Zheng et al, 2003; Jubb et al, 2006a). In this study the expression of CA9 was not prognostic in terms of overall survival, in contrast to a report that expression of CA9 is a poor prognostic factor in colorectal cancer (Cleven et al, 2007). However, the series described by Cleven et al (2007) includes rectal cancers that have received neoadjuvant radiotherapy, which may confound their results as hypoxic cells are relatively resistant to radiation-induced cell death (Wouters and Brown, 1997). Unlike other published studies on hypoxia in colorectal cancer, no patients in this series of colon cancers received neoadjuvant therapy. Therefore, treatment effects do not confound the data presented in this study.

The association between HIF- $2 \alpha$ and prognosis in colon cancer is consistent with previously published reports in two series of colorectal cancers (Yoshimura et al, 2004; Cleven et al, 2007), although our paper is the first to report the effect of HIF- $2 \alpha$ in a large series of large intestinal cancers that have not received radiotherapy. Mathematical modelling suggests that hypoxic microenvironments provide evolutionary pressure, clonally selecting more aggressive neoplastic cells that are able to survive hypoxic stress (Anderson et al, 2006). Moreover, molecular markers of hypoxia have been associated with radiation treatment failure in rectal cancer (Korkeila et al, 2009). Together, these data suggest that cancers expressing HIF- $2 \alpha$ are more aggressive and may warrant more intensive treatment.

This study has two principal limitations. First, it is exploratory, and although the results largely agree with the literature, they have not been internally validated. Limitations of sample size mean that the study is not adequately powered to detect small but statistically significant differences in survival between subsets. However, such differences are arguably too small to be clinically significant. Second, tissue microarrays are not always suitable for assessing markers of hypoxia and angiogenesis. Nevertheless, provided the cohort is large, there is sufficient core redundancy and the prevalence of positive markers is sufficiently high (as is presented in this study), any effects on the data should be minimised.

In summary, Dll4 is expressed in cancer-associated endothelial cells, but not the endothelium adjacent normal colonic mucosa. This study suggests that tumour endothelial expression of Dll4 may not be a significant prognostic factor, but is significantly associated with VEGF expression. In addition, Dll4 is expressed in some 
neoplastic cells with goblet cell differentiation, suggesting that Notch signalling can have a more direct role in colon cancer oncogenesis. Assessing which patients express Dll4 in their tumour endothelium may be critical in predicting response to new therapies that target Notch or VEGF signalling. Furthermore, the antibody may be useful for imaging the vasculature of tumours before therapy.

\section{ACKNOWLEDGEMENTS}

This study received financial support from Cancer Research UK, the Experimental Cancer Medicine Centre Network, the European

\section{REFERENCES}

Anderson AR, Weaver AM, Cummings PT, Quaranta V (2006) Tumor morphology and phenotypic evolution driven by selective pressure from the microenvironment. Cell 127: 905-915

Appelhoff RJ, Tian YM, Raval RR, Turley H, Harris AL, Pugh CW, Ratcliffe PJ, Gleadle JM (2004) Differential function of the prolyl hydroxylases PHD1, PHD2, and PHD3 in the regulation of hypoxia-inducible factor. J Biol Chem 279: $38458-38465$

Benjamini Y, Hochberg Y (1995) Controlling the false discovery rate: a practical and powerful approach to multiple testing. J R Statist Soc B 57: $289-300$

Bergers G, Javaherian K, Lo KM, Folkman J, Hanahan D (1999) Effects of angiogenesis inhibitors on multistage carcinogenesis in mice. Science 284: $808-812$

Boddy JL, Fox SB, Han C, Campo L, Turley H, Kanga S, Malone PR, Harris $\mathrm{AL}$ (2005) The androgen receptor is significantly associated with vascular endothelial growth factor and hypoxia sensing via hypoxia-inducible factors HIF-1a, HIF-2a, and the prolyl hydroxylases in human prostate cancer. Clin Cancer Res 11: 7658-7663

Bubendorf L, Nocito A, Moch H, Sauter G (2001) Tissue microarray (TMA) technology: miniaturized pathology archives for high-throughput in situ studies. J Pathol 195: $72-79$

Caunt M, Mak J, Liang WC, Stawicki S, Pan Q, Tong RK, Kowalski J, Ho C, Reslan HB, Ross J, Berry L, Kasman I, Zlot C, Cheng Z, Le Couter J, Filvaroff EH, Plowman G, Peale F, French D, Carano R, Koch AW, Wu Y, Watts RJ, Tessier-Lavigne M, Bagri A (2008) Blocking neuropilin-2 function inhibits tumor cell metastasis. Cancer Cell 13: 331-342

Cleven AH, van Engeland M, Wouters BG, de Bruine AP (2007) Stromal expression of hypoxia regulated proteins is an adverse prognostic factor in colorectal carcinomas. Cell Oncol 29: 229-240

D’Angelo G, Duplan E, Boyer N, Vigne P, Frelin C (2003) Hypoxia upregulates prolyl hydroxylase activity: a feedback mechanism that limits HIF-1 responses during reoxygenation. J Biol Chem 278: 38183-38187

Duarte A, Hirashima M, Benedito R, Trindade A, Diniz P, Bekman E, Costa L, Henrique D, Rossant J (2004) Dosage-sensitive requirement for mouse Dll4 in artery development. Genes Dev 18: 2474-2478

Dupont WD, Plummer Jr WD (1990) Power and sample size calculations. A review and computer program. Control Clin Trials 11: 116-128

Ferrara N, Leung DW, Cachianes G, Winer J, Henzel WJ (1991) Purification and cloning of vascular endothelial growth factor secreted by pituitary folliculostellate cells. Methods Enzymol 198: 391-405

Goodlad RA, Ryan AJ, Wedge SR, Pyrah IT, Alferez D, Poulsom R, Smith NR, Mandir N, Watkins AJ, Wilkinson RW (2006) Inhibiting vascular endothelial growth factor receptor-2 signaling reduces tumor burden in the ApcMin/+ mouse model of early intestinal cancer. Carcinogenesis 27: $2133-2139$

Grothey A, Hedrick EE, Mass RD, Sarkar S, Suzuki S, Ramanathan RK, Hurwitz HI, Goldberg RM, Sargent DJ (2008a) Response-independent survival benefit in metastatic colorectal cancer: a comparative analysis of N9741 and AVF2107. J Clin Oncol 26: 183-189

Grothey A, Sugrue MM, Purdie DM, Dong W, Sargent D, Hedrick E, Kozloff M (2008b) Bevacizumab beyond first progression is associated with prolonged overall survival in metastatic colorectal cancer: results from a large observational cohort study (BRiTE). J Clin Oncol 26: 5326-5334

Hanrahan V, Currie M, Gunningham S, Morrin H, Scott P, Robinson B, Fox $S$ (2003) The angiogenic switch for vascular endothelial growth factor (VEGF)-A, VEGF-B, VEGF-C, and VEGF-D in the adenoma-carcinoma sequence during colorectal cancer progression. J Pathol 200: 183-194
Union Metoxia Framework and the NIHR Biomedical Research Centre, Oxford.

\section{Conflict of interest}

Dr Thurston and Dr Noguera-Troise are employees of Regeneron Pharmaceuticals Inc., which is developing a Dll4-related therapy.

Supplementary Information accompanies the paper on British Journal of Cancer website (http://www.nature.com/bjc)
Harrington LS, Sainson RC, Williams CK, Taylor JM, Shi W, Ji JL, Harris AL (2007) Regulation of multiple angiogenic pathways by Dll4 and Notch in human umbilical vein endothelial cells. Microvasc Res 75: 144-154

Hellstrom M, Phng LK, Hofmann JJ, Wallgard E, Coultas L, Lindblom P, Alva J, Nilsson AK, Karlsson L, Gaiano N, Yoon K, Rossant J, IruelaArispe ML, Kalen M, Gerhardt H, Betsholtz C (2007) Dll4 signalling through Notch1 regulates formation of tip cells during angiogenesis. Nature 445: $776-780$

Hurwitz H, Fehrenbacher L, Novotny W, Cartwright T, Hainsworth J, Heim W, Berlin J, Baron A, Griffing S, Holmgren E, Ferrara N, Fyfe G, Rogers B, Ross R, Kabbinavar F (2004) Bevacizumab plus irinotecan, fluorouracil, and leucovorin for metastatic colorectal cancer. $N$ Engl J Med 350: 2335-2342

Ince WL, Jubb AM, Holden SN, Holmgren EB, Tobin P, Sridhar M, Hurwitz HI, Kabbinavar F, Novotny WF, Hillan KJ, Koeppen H (2005) Association of k-ras, b-raf, and p53 status with the treatment effect of bevacizumab. J Natl Cancer Inst 97: 981 -989

Indraccolo S, Minuzzo S, Masiero M, Pusceddu I, Persano L, Moserle L, Reboldi A, Favaro E, Mecarozzi M, Di Mario G, Screpanti I, Ponzoni M, Doglioni C, Amadori A (2009) Cross-talk between tumor and endothelial cells involving the Notch3-Dll4 interaction marks escape from tumor dormancy. Cancer Res 69: 1314-1323

Joyce JA, Laakkonen P, Bernasconi M, Bergers G, Ruoslahti E, Hanahan D (2003) Stage-specific vascular markers revealed by phage display in a mouse model of pancreatic islet tumorigenesis. Cancer Cell 4: 393-403

Jubb AM, Hurwitz HI, Bai W, Holmgren EB, Tobin P, Guerrero AS, Kabbinavar F, Holden SN, Novotny WF, Frantz GD, Hillan KJ, Koeppen $\mathrm{H}$ (2006a) Impact of vascular endothelial growth factor-A expression, thrombospondin-2 expression, and microvessel density on the treatment effect of bevacizumab in metastatic colorectal cancer. J Clin Oncol 24: $217-227$

Jubb AM, Landon TH, Burwick J, Pham TQ, Frantz GD, Cairns B, Quirke P, Peale FV, Hillan KJ (2003) Quantitative analysis of colorectal tissue microarrays by immunofluorescence and in situ hybridization. J Pathol 200: $577-588$

Jubb AM, Oates AJ, Holden S, Koeppen H (2006b) Predicting benefit from anti-angiogenic agents in malignancy. Nat Rev Cancer 6: 626-635

Jubb AM, Pham TQ, Hanby AM, Frantz GD, Peale FV, Wu TD, Koeppen HW, Hillan KJ (2004) Expression of vascular endothelial growth factor, hypoxia inducible factor 1alpha, and carbonic anhydrase IX in human tumours. J Clin Pathol 57: 504-512

Kaluz S, Kaluzova M, Chrastina A, Olive PL, Pastorekova S, Pastorek J, Lerman MI, Stanbridge EJ (2002) Lowered oxygen tension induces expression of the hypoxia marker MN/carbonic anhydrase IX in the absence of hypoxia-inducible factor 1 alpha stabilization: a role for phosphatidylinositol 3'-kinase. Cancer Res 62: 4469-4477

Kim KJ, Li B, Winer J, Armanini M, Gillett N, Phillips HS, Ferrara N (1993) Inhibition of vascular endothelial growth factor-induced angiogenesis suppresses tumour growth in vivo. Nature 362: 841-844

Knowles HJ, Raval RR, Harris AL, Ratcliffe PJ (2003) Effect of ascorbate on the activity of hypoxia-inducible factor in cancer cells. Cancer Res 63: $1764-1768$

Korkeila E, Talvinen K, Jaakkola PM, Minn H, Syrjanen K, Sundstrom J, Pyrhonen S (2009) Expression of carbonic anhydrase IX suggests poor outcome in rectal cancer. Br J Cancer 100: $874-880$

Korsisaari N, Kasman IM, Forrest WF, Pal N, Bai W, Fuh G, Peale FV, Smits R, Ferrara N (2007) Inhibition of VEGF-A prevents the angiogenic switch 
and results in increased survival of Apc+/min mice. Proc Natl Acad Sci USA 104: 10625 - 10630

Li JL, Sainson RC, Shi W, Leek R, Harrington LS, Preusser M, Biswas S, Turley H, Heikamp E, Hainfellner JA, Harris AL (2007) Delta-like 4 Notch ligand regulates tumor angiogenesis, improves tumor vascular function, and promotes tumor growth in vivo. Cancer Res 67: 11244-11253

Loncaster JA, Harris AL, Davidson SE, Logue JP, Hunter RD, Wycoff CC, Pastorek J, Ratcliffe PJ, Stratford IJ, West CM (2001) Carbonic anhydrase (CA IX) expression, a potential new intrinsic marker of hypoxia: correlations with tumor oxygen measurements and prognosis in locally advanced carcinoma of the cervix. Cancer Res 61: 6394-6399

Mailhos C, Modlich U, Lewis J, Harris A, Bicknell R, Ish-Horowicz D (2001) Delta4, an endothelial specific notch ligand expressed at sites of physiological and tumor angiogenesis. Differentiation 69: 135-144

McShane LM, Altman DG, Sauerbrei W, Taube SE, Gion M, Clark GM (2005) Reporting recommendations for tumor marker prognostic studies (REMARK). J Natl Cancer Inst 97: 1180-1184

Mizukami Y, Li J, Zhang X, Zimmer MA, Iliopoulos O, Chung DC (2004) Hypoxia-inducible factor-1-independent regulation of vascular endothelial growth factor by hypoxia in colon cancer. Cancer Res 64: 1765-1772

Nanni O, Volpi A, Frassineti GL, De Paola F, Granato AM, Dubini A, Zoli W, Scarpi E, Turci D, Oliverio G, Gambi A, Amadori D (2002) Role of biological markers in the clinical outcome of colon cancer. Br J Cancer 87: $868-875$

Noguera-Troise I, Daly C, Papadopoulos NJ, Coetzee S, Boland P, Gale NW, Lin HC, Yancopoulos GD, Thurston G (2006) Blockade of Dll4 inhibits tumour growth by promoting non-productive angiogenesis. Nature 444: $1032-1037$

Pan Q, Chanthery Y, Liang WC, Stawicki S, Mak J, Rathore N, Tong RK, Kowalski J, Yee SF, Pacheco G, Ross S, Cheng Z, Le Couter J, Plowman G, Peale F, Koch AW, Wu Y, Bagri A, Tessier-Lavigne M, Watts RJ (2007) Blocking neuropilin-1 function has an additive effect with anti-VEGF to inhibit tumor growth. Cancer Cell 11: 53-67

Parkin DM, Bray F, Ferlay J, Pisani P (2005) Global cancer statistics, 2002. CA Cancer J Clin 55: 74-108

Pastorekova S, Zavadova Z, Kostal M, Babusikova O, Zavada J (1992) A novel quasi-viral agent, $\mathrm{MaTu}$, is a two-component system. Virology 187: $620-626$

Patel NS, Dobbie MS, Rochester M, Steers G, Poulsom R, Le Monnier K, Cranston DW, Li JL, Harris AL (2006) Up-regulation of endothelial deltalike 4 expression correlates with vessel maturation in bladder cancer. Clin Cancer Res 12: $4836-4844$

Patel NS, Li JL, Generali D, Poulsom R, Cranston DW, Harris AL (2005) Up-regulation of delta-like 4 ligand in human tumor vasculature and the role of basal expression in endothelial cell function. Cancer Res 65: $8690-8697$

Poulsom R, Longcroft JM, Jeffery RE, Rogers LA, Steel JH (1998) A robust method for isotopic riboprobe in situ hybridisation to localise mRNAs in routine pathology specimens. Eur J Histochem 42: 121-132

Rasheed S, Harris AL, Tekkis PP, Turley H, Silver A, McDonald PJ, Talbot IC, Glynne-Jones R, Northover JM, Guenther T (2009) Assessment of microvessel density and carbonic anhydrase-9 (CA-9) expression in rectal cancer. Pathol Res Pract 205: 1-9

Relf M, LeJeune S, Scott PA, Fox S, Smith K, Leek R, Moghaddam A, Whitehouse R, Bicknell R, Harris AL (1997) Expression of the angiogenic factors vascular endothelial cell growth factor, acidic and basic fibroblast growth factor, tumor growth factor beta-1, platelet-derived endothelial cell growth factor, placenta growth factor, and pleiotrophin in human primary breast cancer and its relation to angiogenesis. Cancer Res 57: 963-969

Ridgway J, Zhang G, Wu Y, Stawicki S, Liang WC, Chanthery Y, Kowalski J, Watts RJ, Callahan C, Kasman I, Singh M, Chien M, Tan C, Hongo JA, de Sauvage F, Plowman G, Yan M (2006) Inhibition of Dll4 signalling inhibits tumour growth by deregulating angiogenesis. Nature 444: $1083-1087$

Sanchez M, Galy B, Muckenthaler MU, Hentze MW (2007) Iron-regulatory proteins limit hypoxia-inducible factor-2alpha expression in iron deficiency. Nat Struct Mol Biol 14: 420-426

Skuli N, Liu L, Runge A, Wang T, Yuan L, Patel S, Iruela-Arispe L, Simon MC, Keith B (2009) Endothelial deletion of hypoxia inducible factor2alpha (HIF-2 $\{$ alphal\}) alters vascular func. Blood 114(2): 469-477

Soilleux EJ, Turley H, Tian YM, Pugh CW, Gatter KC, Harris AL (2005) Use of novel monoclonal antibodies to determine the expression and distribution of the hypoxia regulatory factors PHD-1, PHD-2, PHD-3 and $\mathrm{FIH}$ in normal and neoplastic human tissues. Histopathology 47: $602-610$

Sowter HM, Raval RR, Moore JW, Ratcliffe PJ, Harris AL (2003) Predominant role of hypoxia-inducible transcription factor (Hif)-1alpha versus Hif-2alpha in regulation of the transcriptional response to hypoxia. Cancer Res 63: 6130-6134

Talks KL, Turley H, Gatter KC, Maxwell PH, Pugh CW, Ratcliffe PJ, Harris AL (2000) The expression and distribution of the hypoxia-inducible factors HIF-1alpha and HIF-2alpha in normal human tissues, cancers, and tumor-associated macrophages. Am J Pathol 157: 411-421

Thurston G, Noguera-Troise I, Yancopoulos GD (2007) The Delta paradox: DLL4 blockade leads to more tumour vessels but less tumour growth. Nat Rev Cancer 7: 327-331

Turley H, Scott PA, Watts VM, Bicknell R, Harris AL, Gatter KC (1998) Expression of VEGF in routinely fixed material using a new monoclonal antibody VG1. J Pathol 186: 313-318

van Es JH, van Gijn ME, Riccio O, van den Born M, Vooijs M, Begthel H, Cozijnsen M, Robine S, Winton DJ, Radtke F, Clevers H (2005) Notch/ gamma-secretase inhibition turns proliferative cells in intestinal crypts and adenomas into goblet cells. Nature 435: 959-963

Wiesener MS, Munchenhagen PM, Berger I, Morgan NV, Roigas J, Schwiertz A, Jurgensen JS, Gruber G, Maxwell PH, Loning SA, Frei U, Maher ER, Grone HJ, Eckardt KU (2001) Constitutive activation of hypoxia-inducible genes related to overexpression of hypoxia-inducible factor-1alpha in clear cell renal carcinomas. Cancer Res 61: 5215-5222

Williams CK, Li JL, Murga M, Harris AL, Tosato G (2006) Up-regulation of the Notch ligand Delta-like 4 inhibits VEGF-induced endothelial cell function. Blood 107: $931-939$

Wouters BG, Brown JM (1997) Cells at intermediate oxygen levels can be more important than the 'hypoxic fraction' in determining tumor response to fractionated radiotherapy. Radiat Res 147: 541-550

Yoshimura H, Dhar DK, Kohno H, Kubota H, Fujii T, Ueda S, Kinugasa S, Tachibana M, Nagasue N (2004) Prognostic impact of hypoxia-inducible factors 1alpha and 2alpha in colorectal cancer patients: correlation with tumor angiogenesis and cyclooxygenase-2 expression. Clin Cancer Res 10: $8554-8560$

Zhang X, Gaspard JP, Chung DC (2001) Regulation of vascular endothelial growth factor by the Wnt and K-ras pathways in colonic neoplasia. Cancer Res 61: 6050-6054

Zheng S, Han MY, Xiao ZX, Peng JP, Dong Q (2003) Clinical significance of vascular endothelial growth factor expression and neovascularization in colorectal carcinoma. World J Gastroenterol 9: 1227-1230 